\title{
2 High-resolution mapping of forest vulnerability to 3 wind for disturbance-aware forestry and climate 4 change adaptation
}

5

6

7

\author{
Susanne Suvanto*1, Mikko Peltoniemi ${ }^{1}$, Sakari Tuominen ${ }^{1}$, Mikael Strandström ${ }^{1}$, Aleksi \\ Lehtonen $^{1}$ \\ ${ }^{1}$ Natural Resources Institute Finland (Luke), Latokartanonkaari 9, 00790 Helsinki \\ * Corresponding author
}

\section{Abstract}

Windstorms cause major disturbances in European forests and forest management can play a key role in making forests more persistent to disturbances. However, better information is needed to support decision making that effectively accounts for wind disturbances. Here we show how empirical probability models of wind damage, combined with existing spatial datasets, can be used to provide fine-scale spatial information about disturbance probability over large areas. First, we created stand-level damage probability models with predictors describing forest characteristics, recent forest management history and local wind, soil, site and climate conditions. We tested three different methods for creating the damage probability models - generalized linear models (GLM), generalized additive models (GAM) and boosted regression trees (BRT). Then, the damage probability maps were calculated by combining the models (GLM, GAM and BRT) with GIS data sets representing the model predictors. Finally, we demonstrated the predictive performance of the maps with a large, independent test data, which shows that the damage probability maps are able to identify vulnerable forests also in new wind damage events (AUC > 0.7). Use of the more complex methods (GAM and BRT) was not found to improve the predictive performance of the map compared to GLM, and therefore we would suggest using the more simple GLM method that can be more easily interpreted. The map allows identification of vulnerable forest areas in 
high spatial resolution (16 $\times 16 \mathrm{~m}^{2}$ raster resolution), making it useful in assessing the vulnerability of individual forest stands when making management decisions. The map is also a powerful tool for communicating disturbance risks to forest owners and managers and it has the potential to steer forest management practices to a more disturbance aware direction. Our study showed that in spite of the inherent stochasticity of the wind and damage phenomena at all spatial scales, it can be modelled with good accuracy across large spatial scales when existing ground and earth observation data sources are combined smartly. With improving data quality and availability, map-based risk assessments can be extended to other regions and other disturbance types.

Keywords: forest disturbances; storm damage; windthrow; tree mortality; forest management; climate change

\section{Introduction}

Forest wind disturbances have major economic, societal and ecological consequences in Europe. Forest disturbances have substantial effects on forest productivity and carbon storage (Reyer et al., 2017; Seidl et al., 2014), and therefore actions to reduce and manage the disturbances are crucial in assuring the persistence of the forest carbon sinks. The damage caused by wind storms in European forests has increased during the past century (Gregow et al., 2017; Schelhaas et al., 2003; Seidl et al., 2011) and this trend is expected to continue (Ikonen et al., 2017; Seidl et al., 2017). The question of forest wind disturbances is therefore becoming increasingly important in the future.

Forest management practices play a key role in making forests less vulnerable to wind disturbances. Management driven changes in European forests, such as increasing standing timber volume and promotion of conifer species, have been identified as one of the major causes of increased forest disturbances in Europe during the latter half of the 20th century (Schelhaas et al., 2003; Seidl et al., 2011). If management practices are shifted to reduce forest vulnerability to wind, it may be possible to decrease the negative effects of wind 
bioRxiv preprint doi: https://doi.org/10.1101/666305; this version posted June 10,2019. The copyright holder for this preprint (which was not certified by peer review) is the author/funder, who has granted bioRxiv a license to display the preprint in perpetuity. It is made available under aCC-BY-NC-ND 4.0 International license.

54

55

56

57

58

59

60

61

62

63

64

65

66

67

68

69

70

71

72

disturbances. However, changing the forest management practises to more disturbanceaware direction is not always easy, as illustrated by the 2005 storm Gudrun in southern Sweden. Despite the massive damage and economic losses caused by the storm and the Swedish Forest Agency's recommendations for alternative, less vulnerable, management options, the forest management practises in the area remained largely unchanged after the storm (Andersson et al., 2018; Valinger et al., 2014). This demonstrates that not only is information about the wind damage risks urgently needed to account for disturbances in management decisions, but it is also crucial that this information is in a form that can be effectively used and communicated to forest owners and managers.

The development of remote sensing methods and the progress of open data policies have substantially increased the amount, quality and availability of spatial data relating to forests. This opens new possibilities for detailed spatial estimation of forest sensitivity to disturbances. Vulnerability of forests to wind damage is affected by forest characteristics, forest management as well as the abiotic environment, such as local wind and soil conditions (Mitchell, 2013). For example, probability of wind damage has been shown to increase with tree height and certain species, such as Norway spruce, are particularly vulnerable to wind (Dobbertin, 2002; Peltola et al., 1999; Valinger and Fridman, 2011). Forest management has major effects on wind damage sensitivity, as trees that have grown in sheltered conditions and have later been exposed to wind, because of thinning or clear cut of the neighboring stand, are especially sensitive to damage (Lohmander and Helles, 1987; Peltola et al., 1999; Suvanto et al., 2016). Areas that are exposed to strong wind gusts (Schindler et al., 2016) or where rooting conditions are limited due to soil characteristics (Nicoll et al., 2006) are more predisposed to wind damage. Therefore, in order to provide useful information on forest vulnerability to wind damage, information from several different sources, scales and disciplines needs to be brought together.

Logistic generalized linear models (GLM) have long been applied in statistical modelling of forest wind damage (Lohmander and Helles, 1987; Suvanto et al., 2016; Valinger and 
81 Fridman, 1997). In addition, different approaches allowing more flexible model behaviour

82 than fully parametric GLMs have been used, such as generalized additive models (GAM;

83 Schmidt et al., 2010) that use non-parametric smooth functions to allow more flexibility in the relationship of response variable and predictors (Hastie et al., 2009). Machine learning approaches have also been successfully applied to wind disturbance modeling (see Hanewinkel et al. 2004 for an early example) and recently especially tree-based ensemble models, such as random forests, have been shown to perform well in predicting wind damage (Albrecht et al., 2019; Hart et al., 2019; Kabir et al., 2018; Schindler et al., 2016). While machine learning methods and additive models are able to more flexibly fit the data and account for non-linearities, the GLMs have strengths in their straightforward interpretability and the robustness of predictions (Albrecht et al., 2019; Nakou et al., 2016).

In this study, our goal was to create high-resolution spatial information about forest vulnerability to wind damage in Finland, using an extensive damage observation data set and a large compilation of spatial data sources to achieve this. More specifically, we aimed

to (1) create a damage probability statistical model based on a large data set of wind damage observations in the Finnish National Forest Inventory (NFI), (2) compare three statistical and machine learning methods for creating the model: GLM, GAM and BRT, (3) calculate a damage probability map by combining the model with national extent GIS layers of model predictors, compiled from different sources, and (4) test the performance of the map with independent damage observations from new NFI data.

\section{Material and methods}

\subsection{National Forest Inventory and wind damage observations}

103 In this study, we used stand level wind damage observations from the $11^{\text {th }}$ Finnish national

104 forest inventory (NFI11) to create an empirical model of wind damage probability (Fig. 1).

105 The field work for the NFI11 was conducted from 2009 to 2013 (Korhonen, 2016; Korhonen 
bioRxiv preprint doi: https://doi.org/10.1101/666305; this version posted June 10,2019. The copyright holder for this preprint (which was not certified by peer review) is the author/funder, who has granted bioRxiv a license to display the preprint in perpetuity. It is made available under aCC-BY-NC-ND 4.0 International license.

106

107

108

109

110

et al., 2017). In later stages of the study, we also used NFI12 (field work in 2014 to 2018) to test the created map (see section 2.5).

In our analysis, we only included plots that were defined as forest land. Poorly productive forests were excluded because they are unimportant for forestry and their wind damage risks tend to be small due to low volume of growing stock. In addition, plots on treeless stands or seedling stands without upper canopy layer were excluded because seedlings have very low wind damage probability (8633 plots). Plots with missing data or unrealistic (erroneous) values for any of the used variables were excluded (52 plots). Plots within less than $1 \mathrm{~km}$ from the national border were also excluded, as the data set describing local wind conditions (Venäläinen et al., 2017) had edge effects (214 plots). If a plot was located on the border of two or more forest stands, we only used the data from the stand where the plot centre was located. The final data set consisted of a total of $41392 \mathrm{NFI}$ plots.

Observations of stand level wind damage and an estimate of the damage time is documented in the Finnish NFI (Korhonen, 2016; Tomppo et al., 2011). Here, we used only the wind damage observations that had occurred no more than 5 years before the date of the field visit. Since the field work of NFI11 was done in 2009 to 2013 , the data can contain observations from damage that has occurred between 2004 and 2013. During these years, several high impact storms affected Finland, such as cyclone Dagmar (known as Tapani in Finland) in December 2011 and a series of severe thunderstorms in summer 2010.

The severity of damage was not considered in the analysis, because the degree of damage was only recorded as cumulative effect of all damage agents, and no information of wind damage severity was available in cases where there were more than one damaging agent present. The restriction of the analysis to only severe damage cases would also have limited the number of damage observations available. Therefore, the binary damage variable contains stands with different damage severities. Stand level wind damage was observed at 1070 plots of the total $41392 \mathrm{NFI}$ plots in the dataset. 


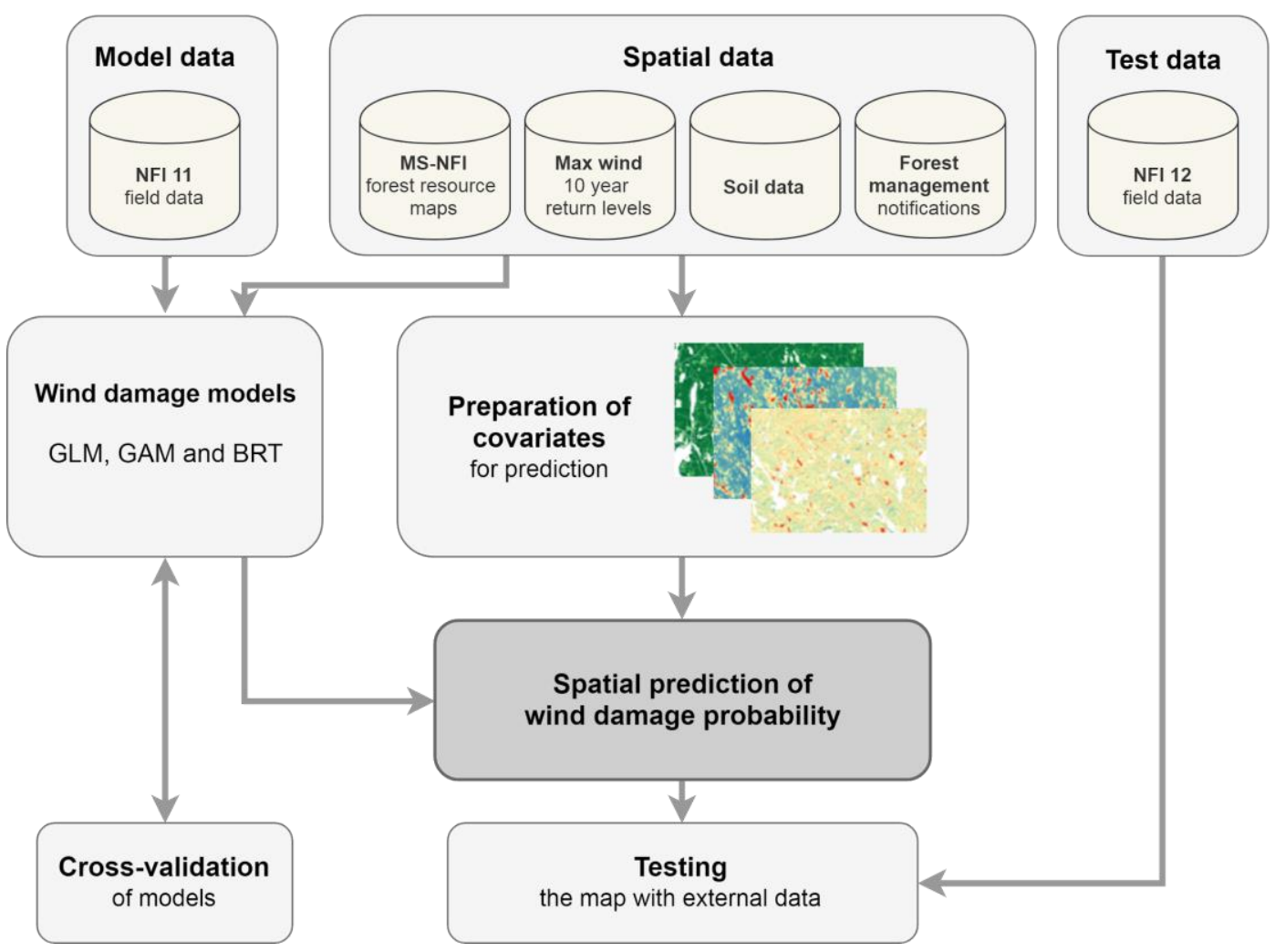

134 Figure 1. General approach and workflow

\subsection{Model predictors}

\subsubsection{National Forest Inventory data}

138 Most predictors in the statistical models were extracted from the NFI field data (Table 1 and 2). To describe the forest characteristics of the stand, dominant tree species and mean tree

140 height in the stand were used. If several canopy layers and species were recorded in the 141 data, the values from the layer with largest tree height were used, as the tallest trees can be 142 assumed to be most vulnerable to wind. The NFI also documents the type and time of most 143 recent forest management operation, and based on this data we created a variable 144 describing the time since last thinning.

$145 \mathrm{NFI}$ information about soil type, soil depth and site fertility was also used (Table 1 and 2).

146 Soil type variable differentiated between organic and mineral soils, as well as fine and 147 coarse grained mineral soils. Fine mineral soils included clay and fine sands, whereas sands 
bioRxiv preprint doi: https://doi.org/10.1101/666305; this version posted June 10,2019. The copyright holder for this preprint (which was not certified by peer review) is the author/funder, who has granted bioRxiv a license to display the preprint in perpetuity. It is made available under aCC-BY-NC-ND 4.0 International license.

148 and coarser soils were classified as coarse mineral soils. Grain size was estimated on the

149 field by NFI teams. Site fertility classes in the NFI are estimated in eight classes, but in our 150 analysis they were regrouped into two classes so that class "Fertile" contained sites from 151 herb-rich to mesic forests on mineral soils and from euthrophic to meso-oligothrophic peatlands. Less fertile classes were included in the "Poor" fertility class (see Tomppo et al., 2011 for detailed description of the site fertility classes used in Finnish NFI).

154 The used data covers the whole country and contains damage observations from several years and several storm events. Therefore, not all plots were exposed to similar wind conditions and this needed to be taken into account in the statistical model. However, we did not have reliable data available about the spatial variation in maximum wind speed conditions during the study period and lacking such an important factor affecting the damage probability is likely to bias the estimation of the effects of other predictors. Therefore, a different approach was taken. To account for areas subjected to severe storm events, variable "Damage density ratio" was calculated using the locations of NFI plots as as the ratio of $2 \mathrm{D}$ kernel density of damaged plots and all plots (Table 1 ). That is, the ratio describes the spatial density of damaged plots in comparison to all NFI plots included in the model and a value of 2 , for example, can therefore be interpreted as two times higher density of damaged plots than what would be expected from the density of all plots. The damage density variable was then transformed into a categorical variable (with classes 0-2, $2-3$, and $>3$ ). The upper limit of the lowest class was set relatively high to identify only the strongest clusters of damaged plots and to avoid catching all the large-scale spatial trends with this variable. The calculations were done in $\mathrm{R}$ with the KernSmooth package (Wand, 2015) using bandwidth of $20 \mathrm{~km}$, see details in S1.

\subsubsection{Other data sets and the delineation of forest stands}

172 In addition to the NFI field data we also supplemented the model predictor set with additional 173 variables describing local wind conditions and open forest borders from other data sources 174 (Table 1 and 2). For the wind conditions, we used a data set describing the local 10-year 
175 return levels of maximum wind speeds in $20 \times 20 \mathrm{~m}^{2}$ raster cells (Venäläinen et al., 2017).

176 That is, the value of each pixel represents the level of maximum wind speed $\left(\mathrm{ms}^{-1}\right)$ expected

177 to be reached on average once in every 10 years. The data is downscaled from coarse-scale

178 wind speed estimates in ERA-Interim reanalyzed data with a wind multiplier approach using

179 CORINE land-use data and digital elevation model (Venäläinen et al., 2017). The data set

180 contains maximum wind speeds calculated for eight different wind directions, and in this

181 study we used the maximum value of these for each pixel. To identify stands with open

182 forest borders (variable 'Open neighbour stand', Table 1), we used the multi-source NFI

183 forest resource maps (MS-NFI; Mäkisara et al., 2016; Tomppo et al., 2008) that combine

184 satellite data and NFI field data to create national extent forest resource maps in a $16 \times 16$

$185 \mathrm{~m}^{2}$ resolution grid.

186 However, the used wind damage observations were documented on the level of forest

187 stands and the stand borders were not mapped in the data but only estimated by the NFI

188 team at the field. Therefore, in order to combine the stand-level damage information with

189 other data sources, the locations of stand borders first needed to be defined. A forest stand

190 in the the Finnish NFI is defined as spatially continuous land area that is homogeneous with

191 respect to properties such as administrative boundaries, site fertility, structure of the growing

192 stock (e.g. maturity class, tree species composition) and forest management (Tomppo et al.,

193 2011). To create polygons that would approximately correspond to the stands assessed in

194 the field by the NFI team, we used image segmentation on the MS-NFI data layers

195 (corresponding to year 2013) describing growing stock volumes by main tree species groups

196 (pine, spruce and deciduous species) and tree height. Land property boundaries obtained

197 from the National Land Survey of Finland were also included in the segmentation, as they

198 are considered as stand boundaries in the NFI. The image segmentation was conducted

199 with the methodology described by Pekkarinen (2002), using the "segmentation by directed

200 trees" algorithm by Narendra and Goldberg (1980). 
bioRxiv preprint doi: https:/doi.org/10.1101/666305; this version posted June 10,2019. The copyright holder for this preprint (which was not certified by peer review) is the author/funder, who has granted bioRxiv a license to display the preprint in perpetuity. It is made available under aCC-BY-NC-ND 4.0 International license.

201 Once the stand polygons were defined with image segmentation, they were used for 202 calculating local wind conditions and finding stands with open stand borders. For each stand 203 polygon, maximum wind-speed within the stand boundaries was calculated (Table 1). 204 Maximum value was used because the NFI field data does not specify the exact location of the damage within the stand, and we assumed that damage occurred in the most wind exposed part of the stand.

To identify plots with open neighbor stands, median tree height was first calculated for each stand polygon using the MS-NFI tree height data. A stand was defined to have an open stand neighbor if the median tree height of any of the stand neighbours was smaller than 5 meters (Table 1). Median was used instead of mean so that it would be less affected by possible outlier values resulting from inaccuracies in defining the stand polygons.

212 Calculations of maximum wind speeds and open stand neighbors for the segments were conducted with PostGIS (version 2.4.0) and Python (version 2.7.12) with packages geopandas (version 0.3.0) and rasterstats (version 0.12.0).

\subsection{Statistical modelling}

216 Damage probability models were created using three different methods: generalized linear

217 models (GLM), generalized additive models (GAM, Wood 2006) and boosted regression

218 trees (BRT; Elith et al., 2008). In all the models the dependent variable was the presence of 219 wind damage in the stand and independent variables described forest characteristics, forest 220 management history, soil and site type, the 10-year return level of maximum wind speed and 221 temperature sum (Table 1).

222 Binomial GLM with logit-link function were fitted in R (version 3.5.1, R Core Team, 2017). To account for non-linear relationships, logarithm transformation were tested for all continuous independent variables and included in the final model if they showed lower AIC than models with non-transformed variables. The transformations were included only for the GLM model, since GAM and BRT enable more flexibility in the shapes of the relationship between 
response variable and predictors, and can therefore account for non-linear relationships without transformations.

Variable selection was based on several criteria: (1) only variables that, based on earlier research, were expected to have a causal effect to wind damage probability were included, (2) since the ultimate goal of the model was to produce the damage probability map, we only 232 included variables for which reasonably high-quality national-extent GIS data sets were available or could be derived from existing data, (3) the behaviour of the variable in the model was plausible based on existing understanding of forest wind damage. We also aimed to build the model so that all major components related to wind damage probability were included. Collinearity of predictors was inspected with Pearson's correlation coefficients and generalized variance inflation factors (GVIF, Fox and Monette, 1992). All correlation between included continuous predictor variables were weaker than 0.5 and GVIFs for all variables were lower than 4.

240 Generalized additive model (GAM) is a generalized linear model with a linear predictor 241 involving a sum of smooth functions of covariates. This specification of the model in terms of 242 smooth functions instead of detailed parametric relationships allows for more flexibility in the 243 dependence of the response of the covariates (Wood, 2017). In our analysis, GAM with logit244 link function was fitted in $\mathrm{R}$ with package mgcv (version 1.8-24, Wood, 2011), using the same predictors that were included in the GLM. All continuous predictors were included in 246 the model through non-linear smoothing spline functions. The dimension parameter (k), 247 effectively setting the upper limit on the degrees of freedom related to the smooth, was set to 24815 for all variables, except for temperature sum for which $k=5$ was chosen to avoid 249 unrealistically fluctuating large-scale patterns in the predictions. The effective degrees of freedom (edf) after fitting the model were lower than $\mathrm{k}$ for all of the terms (see S2 for details), suggesting that the chosen k's were sufficiently large. 
252 Boosted regression trees (BRT) is an ensemble method, that combines a large number of 253 regression trees with a boosting algorithm (Elith et al., 2008). Here, BRTs were computed 254 with R package dismo (version 1.1-4, Hijmans et al., 2017). To find the best parameters, 255 BRTs with different parameter combinations of tree complexity (tested values 1, 2, 3 and 5), 256 learning rate $(0.05,0.01$ and 0.005$)$ and bag fraction $(0.5,0.6$ and 0.75$)$ were fitted. The number of trees was not assigned manually, but was estimated with k-fold cross-validation using the function gbm.step (Hijmans et al., 2017). To estimate the number of trees and to compare different parameter combinations, gbm.step was run separately for each parameter combination. Following the rule-of-thumb suggested by Elith et al. (2008), we excluded parameter combinations that led to models with fewer than 1000 trees. Thus, the model with parameter combination leading to lowest holdout residual deviance in the cross-validation performed by gbm.step and at least 1000 trees was chosen for the final model (tree complexity $=2$, learning rate $=0.01$, bag fraction $=0.5,2250$ trees, see Supplementary material for details).

To make sure that the unbalanced ratio of damaged versus non-damaged plots did not affect the results, BRTs were fitted also from two balanced datasets where the balancing of the observations was done by (1) undersampling the non-damaged plots or (2) oversampling the damaged plots. In both cases the cross-validated AUCs were very similar to ones calculated from the original unbalanced dataset and, therefore, the original data set was used for the final results.

272 To account for the sampling design, weights based on the forest area each plot represents 273 were used in all models (Korhonen, 2016). For example, in northern Finland the NFI 274 sampling design is sparser and therefore the weight of one plot in modelling is higher. To 275 test if the clustered sampling design had an effect on the results, GLMs and GAMs were also 276 fitted as mixed models (GLMM and GAMM) with plot clusters as random intercepts, using R 277 packages Ime4 (Bates et al., 2015) for GLMM and gamm4 (Wood and Scheipl, 2017) for 278 GAMM. However, as the mixed model predictions (in the scale of the linear predictor, using 
279 only fixed effects for prediction) were highly correlated with the fixed effect model prediction

280 (Pearson's $r=0.998, p<0.001$ for GLM vs GLMM, and $r=0.979, p<0.001$ for GAM vs GAMM)

281 and our interest was in marginal instead of conditional inference, no random effects were

282 included in the final models.

283 The models were validated with 10-fold stratified cross-validation, where number of 284 damaged plots was divided evenly into the folds. In the cross-validation, the variation in 285 damage density variable was not used in the prediction, because the variable was included 286 in the model only to account for spatial structures in storm severity in the data, and in an 287 aimed use case of the models (i.e., estimating damage vulnerability in future events) we would not have this information available. Instead, separate predictions for test-folds were calculated with each class of the damage density variable $(0-2,2-3,>3)$. Then, these three 290 predictions were averaged based on the frequency of each class in the original model data. 291 See details in S1.

292 ROC curves and AUC values were calculated for each iteration of cross-validation and used 293 to assess the performance of the models (see Supplementary material). The ROC curve 294 plots the true positive rate (sensitivity) and true negative rate (specificity) of the model with 295 all possible classification thresholds. The AUC values represent the area under ROC curve and measure the model's ability to discriminate between events and non-events. AUC values of 0.5 corresponds to a situation where the classifier is no better than random (ROC curve along diagonal) and value of 1 a situation where the model perfectly discriminates between events and non-events. As a rule of thumb, AUC values over 0.7 are considered 300 acceptable discrimination between classes, values over 0.8 excellent and values over 0.9 outstanding (Hosmer et al., 2013). 
303 Table 1. Description of predictors used and their sources in the model and in the damage 304 probability map. See section 2.2.1 for details.

\begin{tabular}{|c|c|c|c|c|}
\hline Variable & Type $^{*}$ & Unit / Classes & Source in model & Source in map \\
\hline Tree species & C & $\begin{array}{l}\text { pine, spruce, } \\
\text { other }\end{array}$ & NFI11 & MS-NFI 2015 \\
\hline Tree height & $\mathrm{N}$ & $\mathrm{dm}$ & NFI11 & MS-NFI 2015 \\
\hline $\begin{array}{l}\text { Time since } \\
\text { thinning }\end{array}$ & C & $\begin{array}{l}0-5,6-10 \\
>10 \text { years }\end{array}$ & NFI11 & $\begin{array}{l}\text { MS-NFI } 2015 \\
\text { Forest use notifications }\end{array}$ \\
\hline $\begin{array}{l}\text { Wind (10-year } \\
\text { return level of } \\
\text { max wind speed) }\end{array}$ & $\mathrm{N}$ & $\mathrm{ms}^{-1}$ & $\begin{array}{l}\text { Venäläinen et al. } \\
2017\end{array}$ & Venäläinen et al. 2017 \\
\hline $\begin{array}{l}\text { Open neighbor } \\
\text { stand }\end{array}$ & C & True, False & MS-NFI 2013 & MS-NFI 2015 \\
\hline Soil type & C & $\begin{array}{l}\text { Mineral/coarse, } \\
\text { Mineral/fine, } \\
\text { Organic }\end{array}$ & NFI11 & $\begin{array}{l}\text { GTK 2018, } \\
\text { NLS } 2018\end{array}$ \\
\hline $\begin{array}{l}\text { Mineral soil depth } \\
<30 \mathrm{~cm}\end{array}$ & C & True, False & NFI11 & $\begin{array}{l}\text { GTK } 2018 \\
\text { NLS } 2018\end{array}$ \\
\hline Site fertility & C & Fertile, Poor & NFI11 & MS-NFI 2015 \\
\hline $\begin{array}{l}\text { Temperature sum } \\
\text { (average 1985- } \\
\text { 2014) }\end{array}$ & $\mathrm{N}$ & $\begin{array}{l}100 \text { dd (over } \\
5 C)\end{array}$ & Aalto et al. 2016 & Aalto et al. 2016 \\
\hline $\begin{array}{l}\text { Damage density } \\
\text { ratio }\end{array}$ & C & $0-2,2-3,<3$ & NFI11 & $\begin{array}{l}\text { In the calculation of the } \\
\text { map, this variable was } \\
\text { included as a weighted } \\
\text { average of all classes, } \\
\text { because it was included in } \\
\text { the model only to account } \\
\text { for spatial structures in } \\
\text { storm severity. }\end{array}$ \\
\hline
\end{tabular}


308 Table 2. Descriptive statistics for the NFI11 data. Mean and standard deviation for non309 damaged, damaged and all plots continuous variables, and percentages of each class for

310 categorical variables. The definitions of the variables are in table 1.

\begin{tabular}{llll}
\hline & Non-damaged & Damaged & All \\
\hline Number of plots & 40322 & 1070 & 41392
\end{tabular}

Species

Scots pine

Norway spruce

Other

Tree height

Time since thinning

$$
\begin{aligned}
& 0-5 \text { years } \\
& 6-10 \text { years } \\
& >10 \text { years }
\end{aligned}
$$

Wind

Open neighbor

$$
\text { False }
$$

True

Soil type

Mineral, coarse

Mineral, fine

Organic

Soil depth $<30 \mathrm{~cm}$

$\begin{array}{llll}\text { False } & 89.5 \% & 85.0 \% & 89.4 \% \\ \text { True } & 10.5 \% & 15.0 \% & 10.6 \%\end{array}$

Site fertility

Poor

$34.8 \%$

$65.2 \%$

1185 (178.9)
$59.1 \%$

$63.3 \%$

$24.0 \%$

$36.8 \%$

$24.3 \%$

$12.6 \%$

$4.1 \%$

$12.4 \%$

$163.0(50.5)$

$195.2(45.1)$

$163.9(50.6)$
Fertile

$66.9 \%$

$77.8 \%$

$67.2 \%$

$12.7 \%$

$9.8 \%$

$12.7 \%$

$20.3 \%$

$12.4 \%$

$20.1 \%$

Temperature sum 


\subsection{Calculation of the damage probability map}

313 A GIS raster data layer with resolution of $16 \times 16 \mathrm{~m}^{2}$ and extent of the whole country was prepared for each predictor variable used in the models (Table 1). Forest variables

315 (dominant species, tree height, height-diameter ratio, open forest edge) were derived from

316 the most recent Finnish MS-NFI data for year 2015 (Mäkisara et al., 2019). A grid cell was

317 defined to be on an open forest edge if tree height in the MS-NFI data was lower than 5

318 meters in any of the cell's within a $5 \times 5$ cell neighborhood.

319 Spatial data on forest management history (the time of last thinning) was derived from the 320 forest use notification collected by the Finnish Forest Centre. This data consists of forest use notifications that forest owners are required to report to the Forest Centre before conducting management operations in their forests. For each $16 \times 16 \mathrm{~m}^{2}$ pixel, we first assigned the year of the latest notification of planned thinning in that location of the pixel and then calculated the difference to year 2015 .

Data for the 10-year return rates of maximum wind (Venäläinen et al., 2017) was resampled to the $16 \times 16 \mathrm{~m}^{2}$ grid with GDAL using bilinear interpolation. Soil type was defined as ORGANIC for areas within the peatland polygons in the Topographic Database produced by the National Land Survey of Finland (NLS, 2018). Other areas were defined as mineral soils, and further divided to fine or coarse mineral soils based on the top soil information in the 1:200 000 resolution soil map of the Geological Survey of Finland (GTK, 2018). Data layer for soil fertility classes was made by reclassifying the MS-NFI fertility class data layer from the original five classes to the two classes used in the models (see details in section 2.2.1). Average annual temperature sum was calculated with a threshold of $5^{\circ} \mathrm{C}$ from daily weather data grids (Aalto et al., 2016) for the years 1985 to 2014. the prediction, because we would not have this information available for future events. 
and these three predictions were then averaged based on the frequency of each class in the original model data. See details in S1.

340 The damage probability map was calculated from the GLM, GAM and BRT model objects

341 and the GIS data layers using $R$ packages raster (Hijmans, 2017) and sp (Pebesma and

342 Bivand, 2005).

\subsection{Testing the map with new damage observations}

344 The accuracy of the damage probability map was validated with an independent test data

345 set. The map was compared to the damage observations in the most recent NFI measurements $\left(12^{\text {th }}\right.$ Finnish NFI, NFI12), which were not included in the model fitting data

347 that was from the NFI11. Compared to NFI11, which covers the whole country, NFI12 does

348 not cover the northernmost parts of Finland as plots in the three most northern municipalities

349 (Northern Lapland), where the proportion of forest land is low, are not measured as 350 frequently as other parts of the country.

351 We included the NFI12 plots that had been measured during 2014-2018, were classified as

352 forest land by the field team, and were located within forest area in the MS-NFI forest 353 resource maps (i.e., there were data in the wind damage probability map at the location of 354 the plot). For wind damage we also used the same criteria as with the model data, i.e. only 355 observations estimated to have occurred during the last 5 years were included and the severity of the damage was not considered. In addition, those permanent plots that were measured already in NFI11 were excluded from the test data, as the previous

358 measurements in the same plots were used in the model fitting. The final test data consisted of 33754 plots with wind damage in 734 of the plots.

Values of the wind damage probability maps were extracted at the locations of test data

361 plots as the mean value of map pixels within 20 meter buffer from the location of the plot

362 center. ROC curves and AUC values were calculated from the wind damage information in 363 the test data and the extracted values of the damage probability maps. The extraction was 
conducted in $\mathrm{R}$ with package raster (version 2.8-19, Hijmans, 2017) and ROC/AUC calculations with package $p R O C$ (version 1.12.1, Robin et al., 2011).

366

367

368

369

370

371

372

373

374

375

376

377

378

379

380

381

382

383

\section{Results}

The results showed that forest vulnerability to wind damage is strongly driven by forest characteristics, especially tree height (Figs 2-4, Table 3). In all models, the damage probability increased with tree height, and the increase was strongest for spruce dominated forests. Also forest management affected damage probability in the models, as recently thinned forests and forests with open stand borders were more susceptible to damage. These predictors, related to the forest characteristics, very much drive the fine-scale spatial variation of damage probability in the (Fig. 7).

Wind damage probability was found to show distinct large-scale trends, most importantly the decreasing damage probability from south to north (Fig. 7). This effect in the models comes from the temperature sum, but also other predictors contributed to the large-scale trends in the map, as there as large-scale patterns in wind conditions, forest characteristics and soil and site fertility conditions (Figs 2-4). The north-south pattern in damage density was evident in the damage probability maps with all model methods. However, the map created with the BRT model showed unexpectedly high damage probability values for the northernmost parts of the country (Fig. 7).

The model predictors showed in general rather similar effects in the three tested methods (GLM, GAM and BRT). Yet, there are also differences, especially in the shape of relationship between the continuous predictors and predicted damage probability (Figs 2-4). In GLM, the relationships are restricted to sigmoidal curves, whereas GAM and BRT allow more flexible shapes of responses. This can be seen, for example, in how increasing tree height in pine forests shows steadily increasing damage probability with GLM (Fig. 2) whereas in GAM damage probability peaks around tree height $200 \mathrm{dm}$ and then declines. Higher values of damage density ratio led to higher damage probability in all models, as expected (Fig. 5). 
390 As the BRT predictions are calculated from ensembles of regression trees, they enable very 391 sharp changes in the prediction within small changes in the predictor (Fig. 4). They can also 392 contain diverse interactions between the predictors, which are unfortunately not visible in 393 partial dependence plots like Fig. 4. The BRT results showed somewhat different trends than 394 the other methods in model responses to predictors (Fig. 4). For example, while tree height in spruce forests increases damage probability throughout the range of data in GLM and 396 GAM results (Figs 2-3), in BRT results similar strongly increasing trend is not found, instead 397 the relationship between height and damage probability seems to saturate for all tree 398 species (Fig. 4). The large-scale spatial patterns in map prediction also differed for BRT 399 compared to the other models, as high values of damage probability were predicted for the 400 northernmost parts of the country. (Fig. 7).

401 Cross-validation showed higher predictive performance of the GAM model compared to the 402 GLM and BRT (Fig. 6). However, when the final damage probability maps were tested with 403 the NFI12 test data, all models showed very similar performance in discriminating between 404 damaged and non-damaged plots in the test data. (Fig. 8). All maps gave on average higher 405 damage probability values for damaged than non-damaged plots and showed an acceptable 406 level of discrimination between the two (AUC > 0.7). The added flexibility and ability to 407 account for nonlinear relationships in GAM and BRT did not considerably improve the 408 predictive performance of maps compared to the fully parametric GLM (Fig. 8). 
411 Table 3. GLM model results (for categorical variables, the first class listed in Table 1 is the 412 reference class, and therefore not listed separately in this table).

\begin{tabular}{|c|c|c|c|c|}
\hline & Estimate & Std. Error & $z$ value & $\operatorname{Pr}(>|z|)$ \\
\hline (Intercept) & -14.690 & 1.061 & -13.841 & $<0.001$ \\
\hline Species/Spruce & -8.494 & 1.918 & -4.430 & $<0.001$ \\
\hline Species/Other & -9.314 & 3.931 & -2.370 & 0.018 \\
\hline $\log ($ Height $)$ & 1.661 & 0.189 & 8.807 & $<0.001$ \\
\hline Last thinning $/ 6-10$ years & -0.298 & 0.113 & -2.637 & 0.008 \\
\hline Last thinning/over 10 years & -0.844 & 0.084 & -9.995 & $<0.001$ \\
\hline $\log ($ Wind $)$ & 0.749 & 0.238 & 3.152 & 0.002 \\
\hline Open stand border / TRUE & 0.310 & 0.095 & 3.284 & 0.001 \\
\hline Soil/mineral, fine & -0.356 & 0.124 & -2.875 & 0.004 \\
\hline Soil/organic & -0.216 & 0.110 & -1.962 & 0.050 \\
\hline Soil depth $<30 \mathrm{~cm} /$ TRUE & 0.214 & 0.106 & 2.011 & 0.044 \\
\hline Site fertility / Fertile & -0.425 & 0.092 & -4.611 & $<0.001$ \\
\hline Temperature sum & 0.096 & 0.025 & 3.843 & $<0.001$ \\
\hline Damage density / 2-3 & 1.104 & 0.088 & 12.498 & $<0.001$ \\
\hline Damage density / >3 & 1.898 & 0.111 & 17.137 & $<0.001$ \\
\hline Species/Spruce : log(Height) & 1.634 & 0.358 & 4.561 & $<0.001$ \\
\hline Species/Other : log(Height) & 1.625 & 0.742 & 2.190 & 0.029 \\
\hline
\end{tabular}



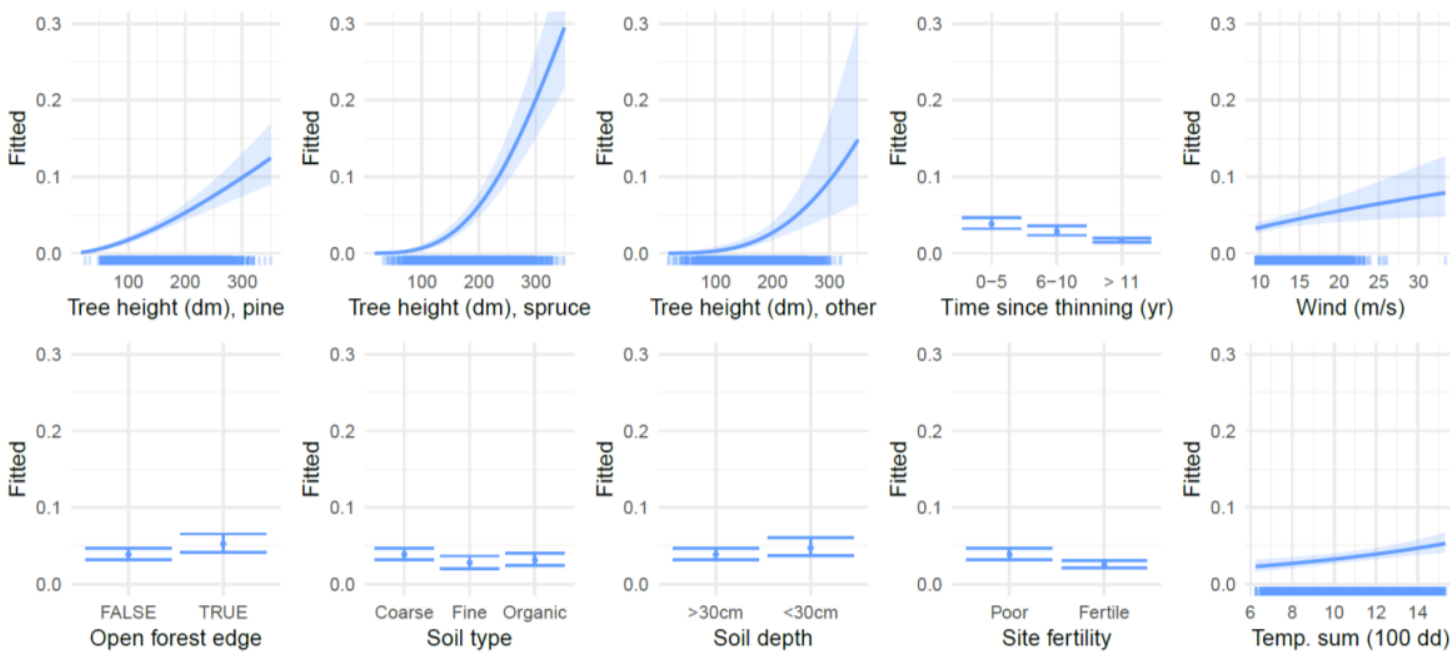

417 Figure 2. GLM partial dependence plots for the map predictors. Prediction of damage 418 probability is calculated for the range of each predictor variable when other predictors are set 419 to average (continuous variables) or reference class (categorical variables). Rugged $\mathrm{x}$-axis describes the distribution of data. Confidence intervals are calculated as $2 \times$ prediction standard error (in the scale of the linear predictor).
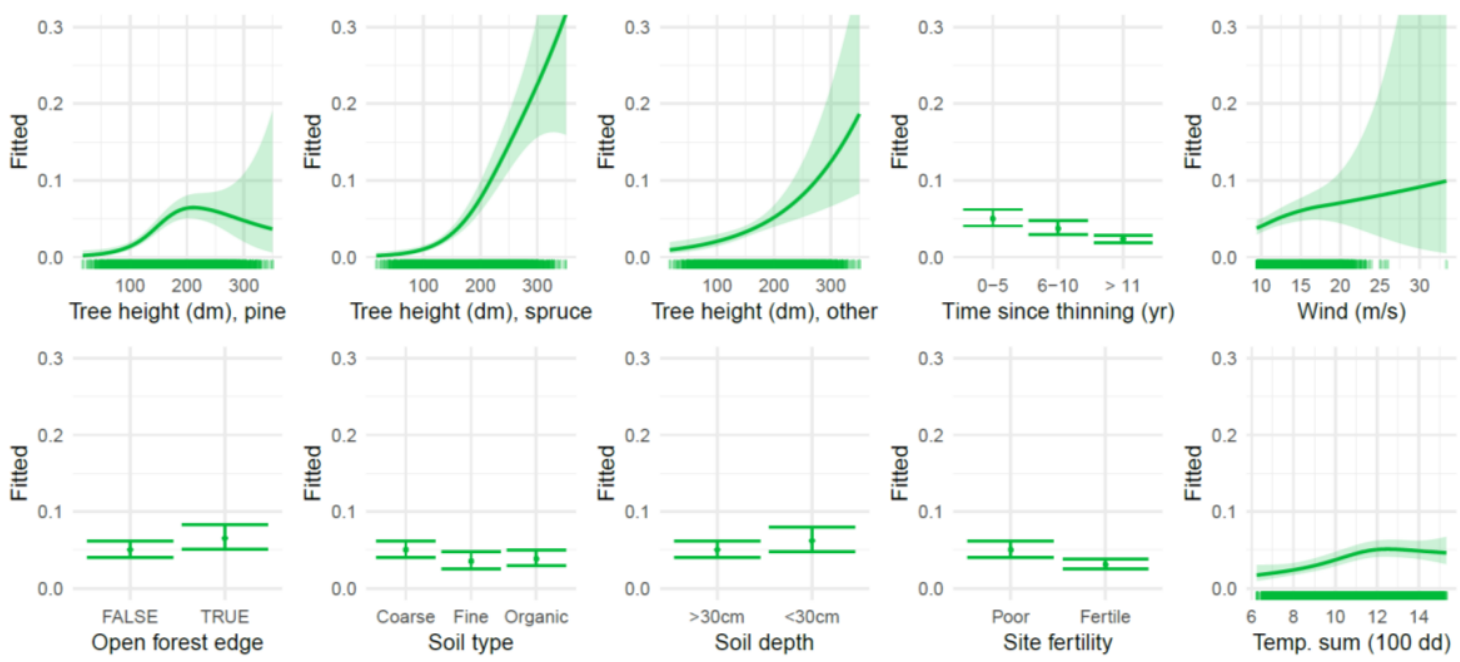

Figure 3. GAM partial dependence plots for the map predictors. Prediction of damage probability is calculated for the range of each predictor variable when other predictors are set to average (continuous variables) or reference class (categorical variables). Rugged x-axis describes the distribution of data. Confidence intervals are calculated as $2 \times$ prediction standard error (in the scale of the linear predictor). 

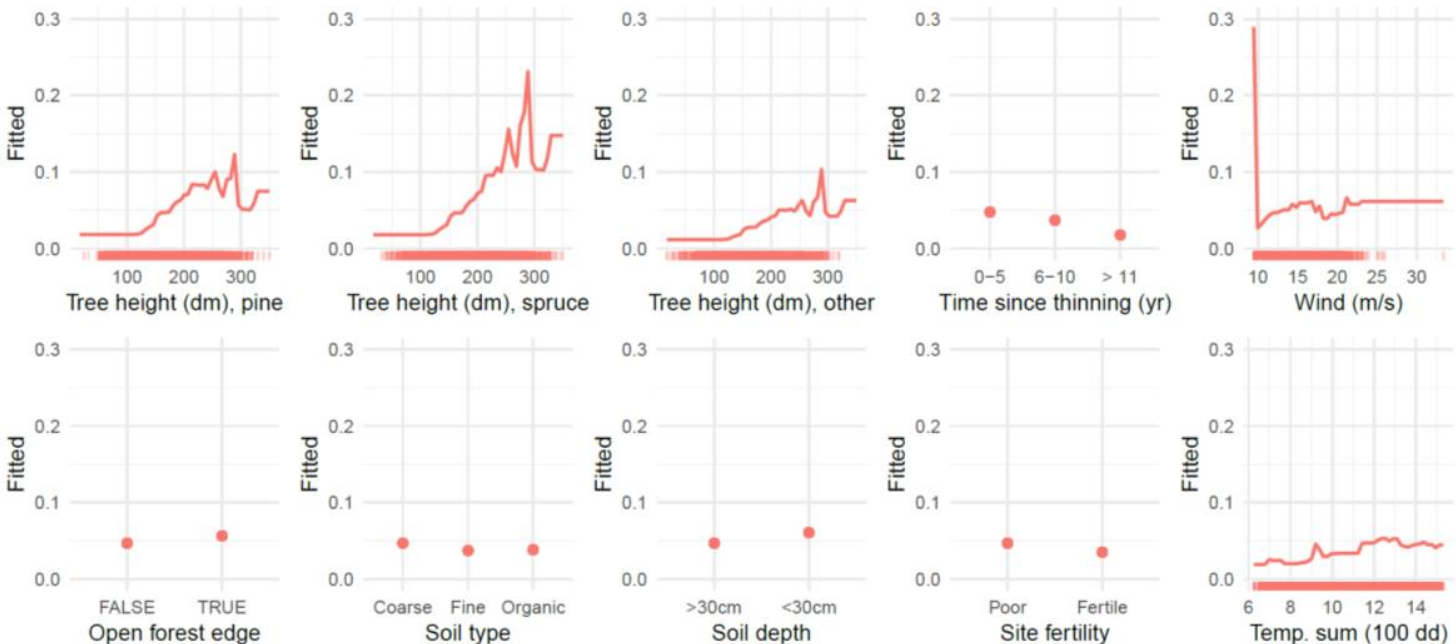

Figure 4. BRT partial dependence plots for the map predictors. Prediction of damage probability is calculated for the range of each predictor variable when other predictors are set to average (continuous variables) or reference class (categorical variables). Rugged $\mathrm{x}$-axis describes the distribution of data.
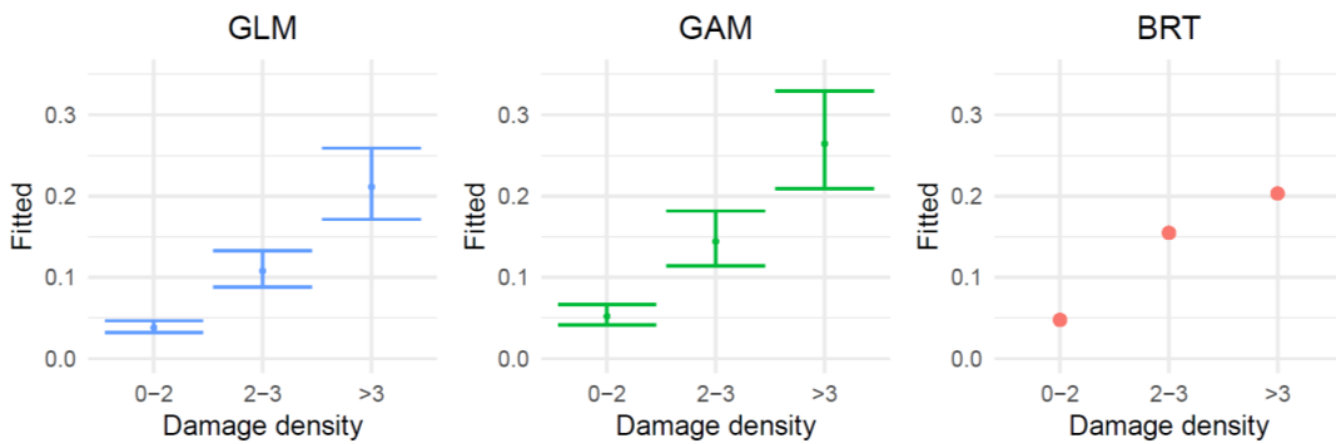

438 Figure 5. Partial dependence plots for damage density in the different models (GLM, GAM and BRT). Damage density was included in the models to account for spatial variation in severity of storm damage in the data, and it was set to 0 when calculating the wind damage probability map. Note that the $y$-axis range differs from figures $2-4$. 
bioRxiv preprint doi: https:/doi.org/10 1101/666305. this version posted June 10 2019. The copyright holder for this preprint (which was not certified by peer review) is the author/funder, who has granted bioRxiv a license to display the preprint in perpetuity. It is made available under aCC-BY-NC-ND 4.0 International license.

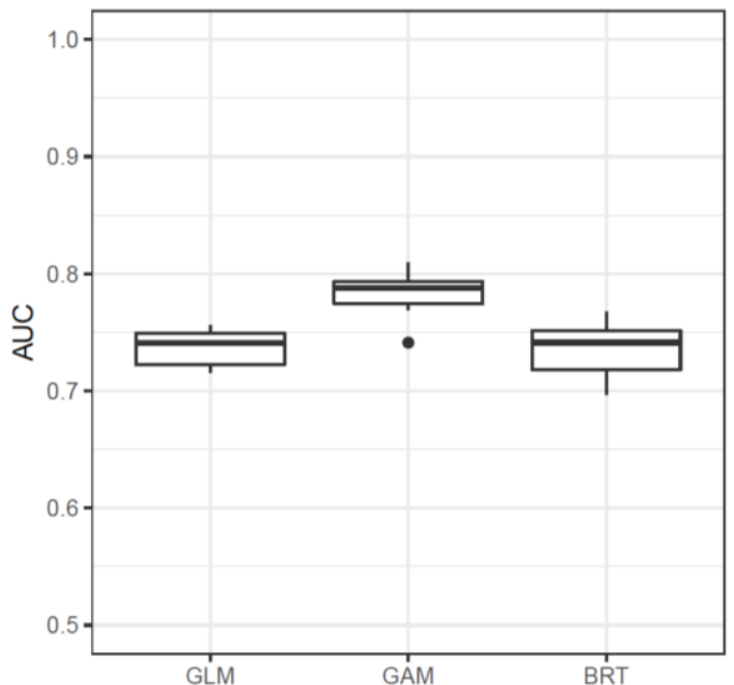

444 Figure 6. Distribution of AUC values in the 10-fold cross-validation for GLM, GAM and BRT. 445
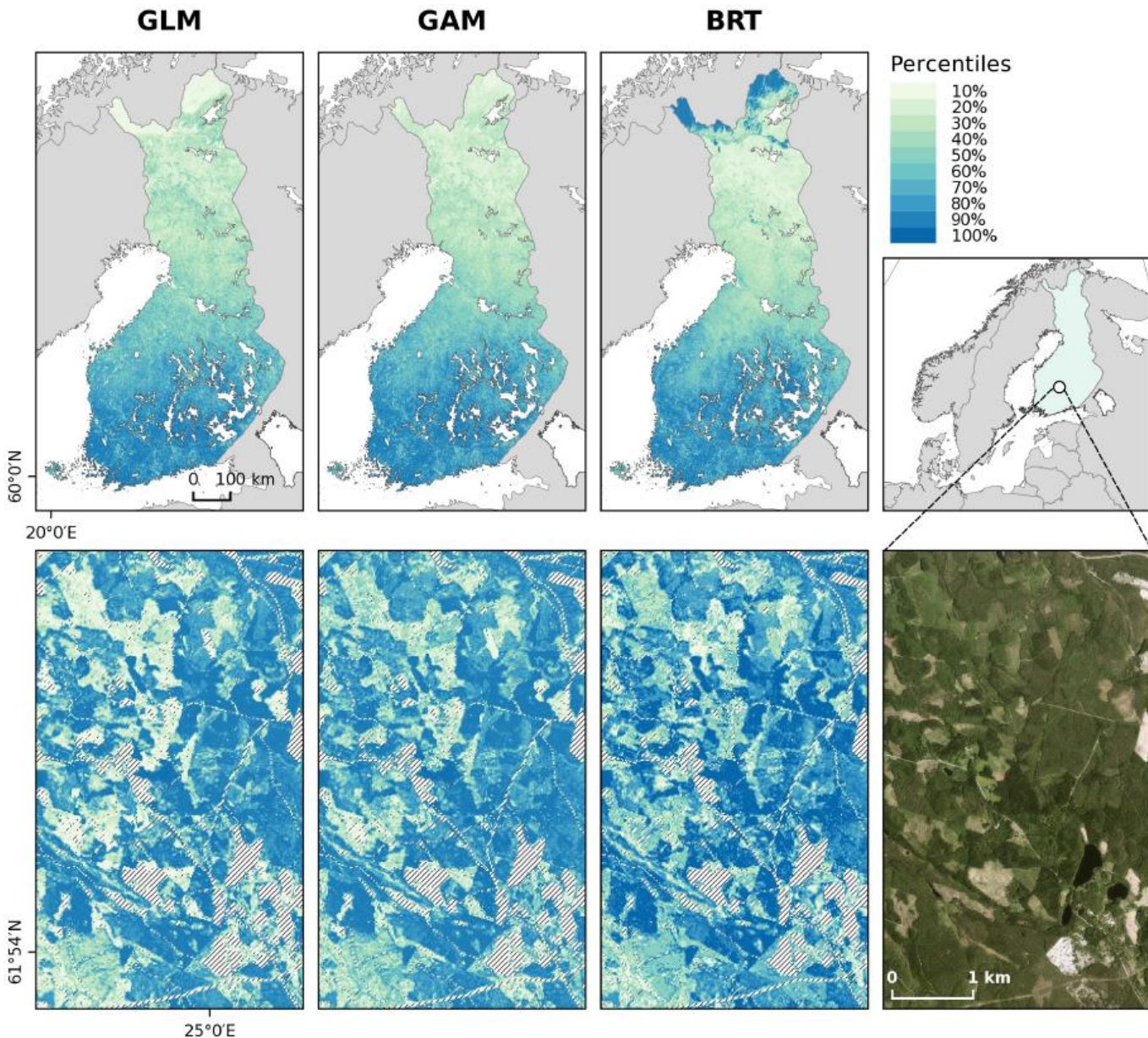

447 Figure 7. Damage vulnerability maps calculated for the whole country (upper panel) and a
448 fine-scale detail of the maps (lower panel), calculated with the three different damage probability models (GLM, GAM and BRT), and an orthophoto from the same location (B). Colors in the damage vulnerability map are defined by the percentiles of the map data (e.g., the first class contain the lowest $10 \%$ of map values). The upper panel maps are resampled 
to $1 \mathrm{~km} \times 1 \mathrm{~km}$ resolution with bilinear interpolation. Note that the orthophoto is not from the exact same time as the forest resource data used for the calculation of the map. Orthophoto
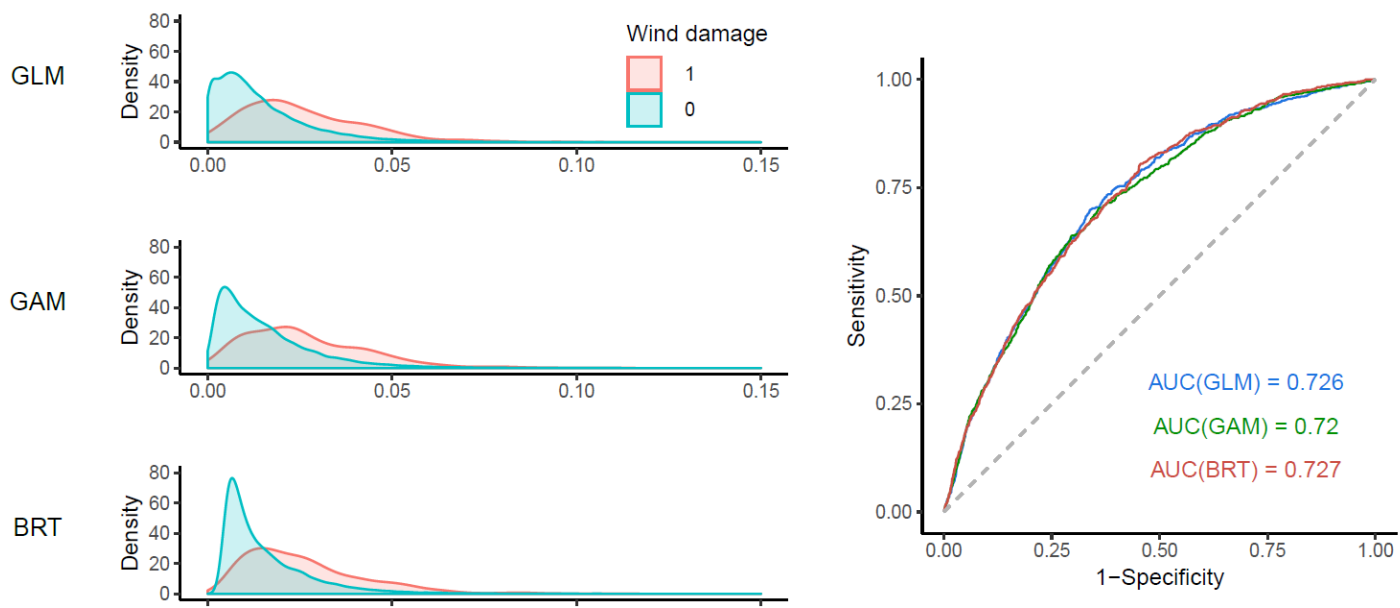

458

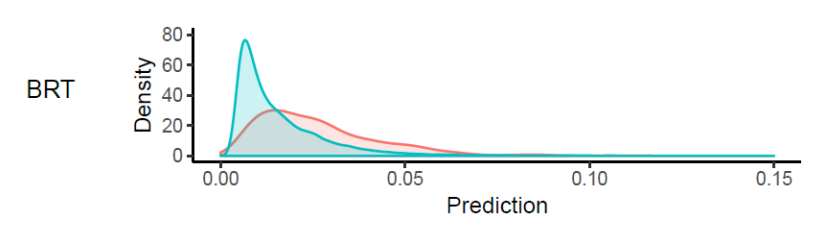

Figure 8. Density plots of the distributions of map predictions for test data plots with wind damage (red) and without wind damage (blue), and ROC curve showing the ability of the maps to distinguish between damaged and non-damaged test plots for the different model methods (GLM, GAM and BRT).

462

463

\section{Discussion}

\subsection{The damage probability map}

465

We created a new spatial wind damage risk product based on inventory data spanning over several years and several other data spatial sources, including information where the actual harvests have recently occurred in Finland. Validation of the map with independent and large data dataset showed that the map is able to identify vulnerable stands also in new storm events. While there have been attempts to map wind damage probability based on empirical damage models (Saarinen et al., 2016; Schindler et al., 2009; Suvanto et al., 2016), our work here uniquely provides national extent and high spatial resolution information about forest vulnerability to wind and is also tested with large external test data. 
473 The successful identification of damage vulnerability in the independent test data is not

474 trivial. First of all, wind damage is challenging to predict and extending the performance of

475 statistical wind damage models to new data sets has been shown not to be straightforward

476 (Fridman and Valinger, 1998; Kamimura et al., 2015; Lanquaye-Opoku and Mitchell, 2005).

477 Moreover, because we wanted to test how well our map identifies forest vulnerability to wind

478 in future events, for which we don't have detailed information of, we did not include any

479 information about spatial distribution of wind speeds or storm events during the time frame of

480 the test data when we tested the map. Thus, the discrimination of damaged from non-

481 damaged plots with fair accuracy $(A \cup C=0.72)$ for the entire extent of Finland indicates that

482 the map is indeed successful in identifying the vulnerable forests, and implies that efficient

483 combination of inventory data and several new spatial data sources is a promising way to

484 map damage risks.

485 A major factor contributing to the successful extension of the map to new test data was the 486 large and systematically sampled forest and damage data that spanned over several years.

487 Thus, our model was able to represent the different conditions (forest characteristics, soil, 488 etc.) within the country. The need for comprehensive model data in empirical wind damage 489 models has been demonstrated, for example, by Hart et al. (2019) who showed that it is 490 possible to generalize to new storm events when the model data covers the variation of 491 predictor variables in the new data set.

492 In addition to good representation of environmental and forest conditions, our data also 493 represents different types of wind events, since the data consisted of damage observations 494 in a 5-year time window. Most wind disturbance studies typically concentrate on one or few 495 storms (e.g., Hart et al., 2019; Kamimura et al., 2015; Saarinen et al., 2016; Schindler et al., 496 2009; Suvanto et al., 2016), which limits their ability to generalize to different storm events. 497 While modelling of multi-event data can be more challenging than single-event data 498 (Albrecht et al., 2019), we argue that it is necessary when the purpose of the model is in assessing damage probability in future events. 
bioRxiv preprint doi: https//doi.org/10.1101/666305; this version posted June 10,2019 . The copyright holder for this preprint (which was not certified by peer review) is the author/funder, who has granted bioRxiv a license to display the preprint in perpetuity. It is made available under aCC-BY-NC-ND 4.0 International license.

500 Availability of high-quality and high-resolution spatial data of the model predictors was also 501 crucial in the successful creation of the damage probability map. Additional uncertainties 502 arise from the input data sets when model predictions are made with GIS data gathered from 503 several different sources instead of the field-measured data that were used for fitting the 504 model. In our case, we were able to utilize several high-quality and high-resolution data sources, such as the MS-NFI raster maps of forest characteristics (Mäkisara et al., 2019) and new data products of local wind conditions (Venäläinen et al., 2017). We were also able

507 to use the recently opened forest use notification data from the Finnish Forest Centre that 508 provided us with nation-wide information about the recent forest management history of the 509 stands. This type of legacy information about forest management is typically difficult to 510 obtain and has rarely been included in predictive wind damage risk models before, despite 511 the clear effects of management history on forest disturbance dynamics. While all these data 512 sources contain uncertainties, the verification of our map with independent test data showed 513 that they were nevertheless able to represent well the main factors determining forest 514 susceptibility to wind.

515 With new data sources and increasing quality and availability of data in the future, the 516 accuracy of the map could still be improved. This could mean, for example, improved 517 accuracy of tree height information through the use of lidar data or inclusion of variables that 518 were left out of the current map due to lack of national level spatial data about their 519 distribution (e.g. distribution of wood decaying fungi that weaken trees' resistance to wind). 520 Soil data had maybe the lowest resolution and higher uncertainties of the used GIS data and, therefore, increased quality of those data sets would also be desirable. However, the effects of soil variables in the model were relatively small, and therefore the effects of only 523 improving the soil GIS data in the prediction would most likely not be drastic. Instead, more 524 detailed soil data would be needed for the model data to improve the description of the role 525 of soil characteristics on tree vulnerability to wind in the model. 


\subsection{Drivers of forest susceptibility to wind disturbance}

527 The factors that were found to affect damage probability in our results are well in line with previously published results. For example, increasing damage probability with tree height and the higher vulnerability of Norway spruce have been shown in previous studies (Peltola et al., 1999; Suvanto et al., 2016; Valinger and Fridman, 2011). New stand edges after clearcutting of the neighboring stand and recently thinned stands have also been known to be at higher risk of windthrow (Lohmander and Helles, 1987; Peltola et al., 1999; Wallentin and Nilsson, 2014).

534 While open stand edges did increase the risk of wind damage in our results, the effect was not as distinct as could be expected from earlier research that emphasizes the role of forest edges (e.g., Peltola et al., 1999). This may in part result from the use of stand level data, where defining and identifying the open stand borders from the NFI data is more uncertain than in the case of tree-level analysis (see section 2.3.2 for the used methodology). Earlier work with storm damage data from severe autumn storms in Finland showed that the effects of open forest edges on damage probability were more emphasized in tree-level analysis

541 (Suvanto et al., 2018) than in the stand-level analysis of the same data (Suvanto et al., 542 2016). In the future, potential improvements to the presentation of damage probability at the forest edges in the map could be achieved by combining tree-level results or mechanistic approaches to the current stand-level modeling approach.

545 In the model, the effect of wind speed data (Venäläinen et al., 2017) on damage probability 546 showed logical behaviour of increasing damage probability with increasing 10-year return

547 rates of maximum wind speed. The wind speed data accounts for the effects of topography on general wind conditions, and therefore variables describing topographical conditions were

549 not included in our models, even though they have been shown to be linked with wind 550 damage probability (e.g., Schindler et al., 2009). 
551 Large-scale geographical patterns in our results showed that the probability of wind damage

552 in Finland decreases from south to north. This is in agreement with results form previous

553 studies combining forest model simulations with mechanistic wind damage models (Ikonen

554 et al., 2017; Peltola et al., 2010). The higher susceptibility of forests in southern Finland to

555 wind disturbances is related to the shorter length of the soil frost period in southern parts of

556 the country. When the soil is frozen, trees are well anchored to the ground and less

557 vulnerable to windthrow and, therefore, forests located in areas with longer periods of soil

558 frost are less likely to be damaged during winter storms (Gregow et al., 2011; Laapas et al.,

559 2019) (Gregow et al., 2011). However, other factors affecting forest wind susceptibility also

560 change along the north-south gradient. The proportion of Scots pine, a species more

561 resistant to wind than Norway spruce, increases towards north, and trees in the north have

562 on average lower height-to-diameter ratio, which is linked to wind damage sensitivity (Ikonen

563 et al., 2017; Peltola et al., 2010). In addition, in southern parts of the country, forest stands

564 are smaller in area and there are less protected areas compared to the north. Thus, more

565 frequent windthrows related to new stand edges and recent thinnings may also contribute to

566 higher damage probability in the south. Similarly, butt rot caused by Heterobasidion sp.,

567 which increases tree vulnerability to wind (Honkaniemi et al., 2017), currently affects the

568 southern parts of the country more severely (Mattila and Nuutinen, 2007; Müller et al., 2018)

569 and may also contribute to the north-south pattern in the wind damage probability in our

570 results. Therefore, it is not entirely clear what are the exact mechanisms causing increased

571 damage probability with temperature sum in our model.

573 While the results for GLM and GAM models were rather similar, the BRT showed rather 574 different model behaviour and large scale prediction patterns. The lack of test data in the northernmost parts of the country makes the interpretation of the test results (Fig. 8) for the

576 BRT a bit challenging, as the area with unexpected BRT predictions is mainly not covered by 
577 the test data. In any case, the high values of BRT predictions in northernmost Finland do not

578 seem realistic.

579 Our results did not show improved predictive performance of the map with the more flexible 580 methods GAM and BRT compared to the logistic regression model (GLM). This is somewhat 581 surprising, especially in the case of BRTs, because several recent studies have shown good 582 performance of random forest for modelling storm disturbances (Albrecht et al., 2019; Hart et 583 al., 2019; Kabir et al., 2018). Yet, in our results BRT did not lead to better predictive 584 performance in cross-validation or with test data, even though it is a tree-based ensemble method very similar to random forest.

586 Our analysis differs from that of these earlier studies (Albrecht et al., 2019; Hart et al., 2019; 587 Kabir et al., 2018) on a few aspects. First, we modelled wind damage on the level of forest stands, whereas the above mentioned studies were operating on tree-level. Second, we were using longer term NFI damage observations whereas most others used data from specific storm events. However, the study by Albrecht et al. (2019) contained both eventspecific and non-event-specific data and they found random forests to outperform GLMs in both types of data. Third, we performed the cross-validation without considering the spatial variation in the storm conditions (the damage density variable in our analysis). This was done because we did not want to use this variable in the prediction, as the final aim was to generalize the results to future damage events, where this information would not be available. It is possible that this approach is disadvantageous to the BRT. All these

597 differences in the approaches and analysis may have contributed in different performance of 598 methods between the studies.

599 On the other hand, while the above mentioned studies did find machine learning methods 600 outperform traditional statistical models in many ways, they also showed some positive sides 601 of the logistic models. Most importantly, even though random forests showed superior 602 performance when cross-validating models with data from one storm event in Hart et al. 
603 (2019), logistic models showed the highest AUC values compared to the other methods

604 when the model was applied to another storm event, supporting the value of GLMs when

605 generalizing the results to new storm events.

606 It seems that while machine learning methods such as BRT and random forest have

607 advantages in accounting for more complex relationships and interactions in the data, they

608 also catch patterns that are not helpful in estimating future disturbance probabilities (see,

609 e.g., the unrealisticly high probabilities of damage with very low wind speeds in BRT, Fig. 4).

610 This is likely to hamper the performance of BRTs so that they are not able to improve cross-

611 validation performance compared to GLM.

612 Use of GLMs has the extra benefit of being more easily communicated to the end user, and

613 they can be easily applied to new use cases when model coefficient estimates are

614 published. The interpretation of relationships between predictors and the response variable

615 is more straightforward, whereas especially in BRTs very small changes in e.g. tree height

616 can lead to drastic changes in model prediction (Fig. 4). The unexpectedly high damage

617 probability values in northern Finland also demonstrate the unpredictability of BRT model

618 behaviour. This aspect is particularly important when the end product is meant to be used in

619 practical applications.

\subsection{Applications and use of the maps}

621 The strength of the map is in its high resolution and large extent. The high-resolution makes

622 it useful for assessing wind damage susceptibility of individual forest stands in fragmented

623 forest landscapes where spatial variation of forest characteristics is high. On the other hand,

624 the national extent of the map makes it widely available and accessible to everyone who is

625 making forest management decisions in Finnish forests. To further improve the accessibility

626 and usability of the map, we created an openly available web map application, where users

627 can explore the map and find the estimated wind damage vulnerabilities of the forests they

628 are interested in, without expert knowledge in GIS software (see 
bioRxiv preprint doi: https://doi.org/10.1101/666305; this version posted June 10,2019 . The copyright holder for this preprint (which was not certified by peer review) is the author/funder, who has granted bioRxiv a license to display the preprint in perpetuity. It is made available under aCC-BY-NC-ND 4.0 International license.

629 https://metsainfo.luke.fi/en/tuulituhoriskikartta, currently only in Finnish, click "Tuulituhoriskit"

630 box to see the wind damage vulnerability map). By providing an effective tool for identifying

631 the vulnerable stands and for communicating wind damage risks to forest managers and 632 owners, the map has potential to steer forest management practices towards a more disturbance-aware direction.

634 In addition to forest management, high-resolution information about forest wind vulnerability 635 is crucially needed also in other sectors and applications. For example, the map can help in 636 identifying high-risk locations where windthrown trees can harm infrastructure by damaging 637 power lines and blocking roads. Insurance companies may also use high-resolution vulnerability information for a more risk based pricing of forest insurances.

While wind disturbances have major consequences from the human point of view, they are a natural process and have an important role in shaping the structure and function of forest ecosystems (Bouget and Duelli, 2004; Kuuluvainen, 2002). By exploring the drivers and spatial variability of wind disturbance dynamics, our results can therefore provide insight in

643 current disturbance regime and its effects in the ecosystem, such as biodiversity and carbon

644 cycling. Improved information about forest disturbances and tree mortality is also urgently 645 needed for vegetation models from stand to global scales to understand how forests will react to the changing climate (Bugmann et al., 2019; Friend et al., 2014).

647 When applying the map in practice, it is important to consider its limitations. First, the 648 damage probabilities in the map are in reference to the damage happened during the study 649 period. The amount of wind damage varies strongly between years and future conditions are not likely to exactly match the conditions during the period from which the data comes from.

651 Therefore, instead of exact probability values, it is better to interpret the map values as 652 relative differences in damage vulnerability. Second, it is important to note that the damage 653 probabilities do not only refer to complete damage of the stand, as our analysis also included 654 less severe damage cases and we did not account for damage severity. Third, it is good to 
655 keep in mind that the map presents forest vulnerability to wind and it is not possible to

656 predict the exact location of future wind disturbances, as there are many things - such as

657 tracks and meteorological conditions of future storms - that can't be accounted for in the

658 map. The uncertainties need to be taken into consideration when using the map.

659 Wind disturbances are strongly linked to other processes of the forest and, therefore, should 660 be considered in larger context. Thus, the greatest benefits of our results can perhaps be 661 achieved by combining it with information and understanding of other processes that control 662 forest ecosystems and forest management decisions. For example, the risk model can be coupled with forest growth simulators and thereafter storm damage risks of different forest management strategies can be evaluated simultaneously when making future scenarios of forests. The map can be combined with spatial information of wood volumes and prices to assess economic risks wind disturbances. Combining wind disturbance results with the dynamics of other disturbance agents is also crucial, as wind damage is strongly linked to bark beetle outbreaks and root rot, and these interactions are becoming increasingly important with the changing climate (Seidl et al., 2017; Seidl and Rammer, 2017). A comprehensive approach is therefore needed to understand and effectively manage wind 671 disturbances in forests.

\section{5. Conclusions}

673 In this study, we show how probability models based on NFI damage observations combined

674 with existing spatial datasets can be used to provide a fine-scale large-extent map of wind 675 disturbance probability. We also demonstrate the ability of the map to identify vulnerable 676 stands in future events with an extensive external test data. These maps provide a powerful 677 tool for supporting disturbance-aware management decisions, communicating disturbance 678 risks to forest owners, and accounting for the effects of windthrown trees in other sectors, such as maintenance of powerline infrastructures. 
680 Our results show that machine learning methods, such as BRT, do not always provide

681 superior results compared to traditional statistical models. As their interpretation in also less

682 straightforward, they can sometimes lead to unpredictable prediction outcomes. Therefore, it

683 is crucial to always assess the benefits of different approaches and to carefully test the

684 performance of the used method with test data that is not used in model fitting. Partial 685 dependence plots and other ways for exploration of model predictions in different situations 686 also provide useful tools for assessing if model behaviour is realistic and biologically 687 plausible.

688 The success of our results is based on large and representative model data as well as highquality and high-resolution GIS data used as map inputs. In Finland, good data sets for both

690 the model fitting and the map inputs are available, which enabled work done in this study.

691 However, with improving data quality and availability (for both damage observations for 692 model fitting and GIS data for map inputs), similar work could be extended to other regions 693 and even to other disturbance types.

\section{Acknowledgements}

695 The research was funded by Finnish Forest Foundation (project MyrskyPuu). We thank Ari 696 Venäläinen and Mikko Laapas from the Finnish Meteorological Institute for their advice and 697 the maximum wind speed 10-year return level data, and the MyrskyPuu project steering 698 group (Liisa Mäkijärvi, Erno Järvinen, Heli Peltola, Ari Venäläinen and Eero Mikkola) for the 699 discussions and their insights on the topic. We also thank Kari T. Korhonen for his 700 comments on the manuscript and the whole NFI team in Luke for the NFI data we were able 701 to use in the study. We acknowledge CSC - IT Center for Science, Finland, for 702 computational resources. 


\section{References}

704

705

706

707

708

709

710

711

712

713

714

715

716

717

718

719

720

721

722

723

724

725

726

727

728

729

730

Aalto, J., Pirinen, P., Jylhä, K., 2016. New gridded daily climatology of Finland: Permutationbased uncertainty estimates and temporal trends in climate. J. Geophys. Res. Atmospheres 121, 3807-3823. https://doi.org/10.1002/2015JD024651

Albrecht, A.T., Jung, C., Schindler, D., 2019. Improving empirical storm damage models by coupling with high-resolution gust speed data. Agric. For. Meteorol. 268, 23-31. https://doi.org/10.1016/j.agrformet.2018.12.017

Andersson, E., Keskitalo, E.C.H., Bergstén, S., 2018. In the eye of the storm: adaptation logics of forest owners in management and planning in Swedish areas. Scand. J. For. Res. 33, 800-808. https://doi.org/10.1080/02827581.2018.1494305

Bates, D., Mächler, M., Bolker, B., Walker, S., 2015. Fitting Linear Mixed-Effects Models Using Ime4. J. Stat. Softw. 67, 1-48. https://doi.org/10.18637/jss.v067.i01

Bouget, C., Duelli, P., 2004. The effects of windthrow on forest insect communities: a literature review. Biol. Conserv. 118, 281-299. https://doi.org/10.1016/j.biocon.2003.09.009

Bugmann, H., Seidl, R., Hartig, F., Bohn, F., Brůna, J., Cailleret, M., François, L., Heinke, J., Henrot, A.-J., Hickler, T., Hülsmann, L., Huth, A., Jacquemin, I., Kollas, C., LaschBorn, P., Lexer, M.J., Merganič, J., Merganičová, K., Mette, T., Miranda, B.R., NadalSala, D., Rammer, W., Rammig, A., Reineking, B., Roedig, E., Sabaté, S., Steinkamp, J., Suckow, F., Vacchiano, G., Wild, J., Xu, C., Reyer, C.P.O., 2019. Tree mortality submodels drive simulated long-term forest dynamics: assessing 15 models from the stand to global scale. Ecosphere 10, e02616. https://doi.org/10.1002/ecs2.2616

Dobbertin, M., 2002. Influence of stand structure and site factors on wind damage comparing the storms Vivian and Lothar. For. Snow Landsc. Res. 77, 187-205.

Elith, J., Leathwick, J.R., Hastie, T., 2008. A working guide to boosted regression trees. J. Anim. Ecol. 77, 802-813. https://doi.org/10.1111/j.1365-2656.2008.01390.x 
731 Fox, J., Monette, G., 1992. Generalized Collinearity Diagnostics. J. Am. Stat. Assoc. 87, 178-183. https://doi.org/10.1080/01621459.1992.10475190

Fridman, J., Valinger, E., 1998. Modelling probability of snow and wind damage using tree, stand, and site characteristics from Pinus sylvestris sample plots. Scand. J. For. Res. 13, 348-356. https://doi.org/10.1080/02827589809382994

Friend, A.D., Lucht, W., Rademacher, T.T., Keribin, R., Betts, R., Cadule, P., Ciais, P., Clark, D.B., Dankers, R., Falloon, P.D., Ito, A., Kahana, R., Kleidon, A., Lomas, M.R., Nishina, K., Ostberg, S., Pavlick, R., Peylin, P., Schaphoff, S., Vuichard, N., Warszawski, L., Wiltshire, A., Woodward, F.I., 2014. Carbon residence time dominates uncertainty in terrestrial vegetation responses to future climate and atmospheric CO2. Proc. Natl. Acad. Sci. 111, 3280-3285. https://doi.org/10.1073/pnas.1222477110

Gregow, H., Laaksonen, A., Alper, M.E., 2017. Increasing large scale windstorm damage in Western, Central and Northern European forests, 1951-2010. Sci. Rep. 7, 46397. https://doi.org/10.1038/srep46397

Gregow, H., Peltola, H., Laapas, M., Saku, S., Venäläinen, A., 2011. Combined occurrence of wind, snow loading and soil frost with implications for risks to forestry in Finland under the current and changing climatic conditions. Silva Fenn. 45. https://doi.org/10.14214/sf.30

GTK, 2018. Superficial deposits of Finland 1:200 000 (sediment polygons). http://tupa.gtk.fi/paikkatieto/meta/maapera_200k.html (accessed 4.29.19).

Hanewinkel, M., Zhou, W., Schill, C., 2004. A neural network approach to identify forest stands susceptible to wind damage. For. Ecol. Manag. 196, 227-243. https://doi.org/10.1016/j.foreco.2004.02.056

Hart, E., Sim, K., Kamimura, K., Meredieu, C., Guyon, D., Gardiner, B., 2019. Use of machine learning techniques to model wind damage to forests. Agric. For. Meteorol.

758 Hastie, T., Tibshirani, R., Friedman, J., 2009. The elements of statistical learning, 2nd ed, 
Springer Series in Statistics. Springer-Verlag New York.

Hijmans, R.J., 2017. raster: Geographic Data Analysis and Modeling. R package version 2.6-7. https://CRAN.R-project.org/package=raster.

Hijmans, R.J., Phillips, S., Leathwick, J., Elith, J., 2017. dismo: Species Distribution Modeling. R package version 1.1-4. https://CRAN.R-project.org/package=dismo.

Honkaniemi, J., Lehtonen, M., Väisänen, H., Peltola, H., 2017. Effects of wood decay by Heterobasidion annosum on the vulnerability of Norway spruce stands to wind damage: a mechanistic modelling approach. Can. J. For. Res. 47, 777-787. https://doi.org/10.1139/cjfr-2016-0505

Hosmer, D.W., Lemeshow, S., Strudivant, R.X., 2013. Applied Logistic Regression, 3rd ed. John Wiley \& Sons, New York.

Ikonen, V.-P., Kilpeläinen, A., Zubizarreta-Gerendiain, A., Strandman, H., Asikainen, A., Venäläinen, A., Kaurola, J., Kangas, J., Peltola, H., 2017. Regional risks of wind damage in boreal forests under changing management and climate projections. Can.

Kabir, E., Guikema, S., Kane, B., 2018. Statistical modeling of tree failures during storms. Reliab. Eng. Syst. Saf. 177, 68-79. https://doi.org/10.1016/j.ress.2018.04.026

Kamimura, K., Gardiner, B., Dupont, S., Guyon, D., Meredieu, C., 2015. Mechanistic and statistical approaches to predicting wind damage to individual maritime pine (Pinus

Korhonen, K.T., 2016. National forest inventories: Assessment of wood availability and use : Publishing, Switzerland, pp. 369-384.

Korhonen, K.T., Ihalainen, A., Ahola, A., Heikkinen, J., Henttonen, H.M., Hotanen, J.-P., 
tutkimus. Natural Resources Institute Finland (Luke).

788

789

790

791

792

793

794

795

796

797

798

799

800

801

802

803

804

805

806

807

808

809

810

811

812

813

814 Narendra, P.M., Goldberg, M., 1980. Image Segmentation with Directed Trees. IEEE Trans.

Kuuluvainen, T., 2002. Disturbance dynamics in boreal forests: defining the ecological basis of restoration and management of biodiversity. Silva Fenn. 36, 5-11.

Laapas, M., Lehtonen, I., Venäläinen, A., Peltola, H.M., 2019. The 10-Year Return Levels of Maximum Wind Speeds under Frozen and Unfrozen Soil Forest Conditions in Finland. Climate 7, 62. https://doi.org/10.3390/cli7050062

Lanquaye-Opoku, N., Mitchell, S.J., 2005. Portability of stand-level empirical windthrow risk models. For. Ecol. Manag. 216, 134-148. https://doi.org/10.1016/j.foreco.2005.05.032

Lohmander, P., Helles, F., 1987. Windthrow probability as a function of stand characteristics and shelter. Scand. J. For. Res. 2, 227-238. https://doi.org/10.1080/02827588709382460

Mäkisara, K., Katila, M., Peräsaari, J., 2019. The Multi-Source National Forest Inventory of Finland - methods and results 2015 (No. 8/2019), Natural Resources and Bioeconomy Studies. Natural Resources Institute Finland (Luke).

Mäkisara, K., Katila, M., Tomppo, E., 2016. The Multi-Source National Forest Inventory of Finland - methods and results 2013 (No. 10/2016), Natural Resources and Bioeconomy Studies. Natural Resources Institute Finland (Luke).

Mattila, U., Nuutinen, T., 2007. Assessing the incidence of butt rot in Norway spruce in southern Finland. Silva Fenn. 41. https://doi.org/10.14214/sf.473

Mitchell, S.J., 2013. Wind as a natural disturbance agent in forests: a synthesis. For. Int. J. For. Res. 86, 147-157. https://doi.org/10.1093/forestry/cps058

Müller, M.M., Henttonen, H.M., Penttilä, R., Kulju, M., Helo, T., Kaitera, J., 2018. Distribution of Heterobasidion butt rot in northern Finland. For. Ecol. Manag. 425, 85-91. https://doi.org/10.1016/j.foreco.2018.05.047

Nakou, A., Sauter, U.H., Kohnle, U., 2016. Improved models of harvest-induced bark damage. Ann. For. Sci. 73, 233-246. https://doi.org/10.1007/s13595-015-0530-5 
Pattern Anal. Mach. Intell. PAMI-2, 185-191.

817 Nicoll, B.C., Gardiner, B.A., Rayner, B., Peace, A.J., 2006. Anchorage of coniferous trees in relation to species, soil type, and rooting depth. Can. J. For. Res. 36, 1871-1883.

NLS, 2018. Topographic Database https://www.maanmittauslaitos.fi/en/maps-and-spatialdata/expert-users/product-descriptions/topographic-database.

Pebesma, E.J., Bivand, R.S., 2005. Classes and methods for spatial data in R (No. 5 (2), https://cran.r-project.org/doc/Rnews/), R News.

Pekkarinen, A., 2002. Image segment-based spectral features in the estimation of timber 4257(02)00052-4

Peltola, H., Ikonen, V.-P., Gregow, H., Strandman, H., Kilpeläinen, A., Venäläinen, A., Kellomäki, S., 2010. Impacts of climate change on timber production and regional risks of wind-induced damage to forests in Finland. For. Ecol. Manag. 260, 833-845. https://doi.org/10.1016/j.foreco.2010.06.001

Peltola, H., Kellomäki, S., Väisänen, H., Ikonen, V.-P., 1999. A mechanistic model for assessing the risk of wind and snow damage to single trees and stands of Scots pine, Norway spruce, and birch. Can. J. For. Res. 29, 647-661. https://doi.org/10.1139/x99-029

R Core Team, 2018. R: A language and environment for statistical computing. R Foundation for Statistical Computing, Vienna, Austria. https://www.R-project.org/. 
productivity changes in European forests? Environ. Res. Lett. 12, 034027. https://doi.org/10.1088/1748-9326/aa5ef1

845 Robin, X., Turck, N., Hainard, A., Tiberti, N., Lisacek, F., Sanchez, J.-C., Müller, M., 2011. pROC: an open-source package for R and $\mathrm{S}+$ to analyze and compare ROC curves. BMC Bioinformatics 12, 77. https://doi.org/10.1186/1471-2105-12-77

848 Saarinen, N., Vastaranta, M., Honkavaara, E., Wulder, M.A., White, J.C., Litkey, P., Holopainen, M., Hyyppä, J., 2016. Using multi-source data to map and model the predisposition of forests to wind disturbance. Scand. J. For. Res. 31, 66-79. https://doi.org/10.1080/02827581.2015.1056751

Schelhaas, M.-J., Nabuurs, G.-J., Schuck, A., 2003. Natural disturbances in the European forests in the 19th and 20th centuries. Glob. Change Biol. 9, 1620-1633. https://doi.org/10.1046/j.1365-2486.2003.00684.x

Schindler, D., Grebhan, K., Albrecht, A., Schönborn, J., 2009. Modelling the wind damage probability in forests in Southwestern Germany for the 1999 winter storm 'Lothar.' Int. J. Biometeorol. 53, 543-554. https://doi.org/10.1007/s00484-009-0242-3

Schindler, D., Jung, C., Buchholz, A., 2016. Using highly resolved maximum gust speed as predictor for forest storm damage caused by the high-impact winter storm Lothar in Southwest Germany. Atmospheric Sci. Lett. 17, 462-469. https://doi.org/10.1002/asl.679

Schmidt, M., Hanewinkel, M., Kändler, G., Kublin, E., Kohnle, U., 2010. An inventory-based approach for modeling single-tree storm damage - experiences with the winter storm of 1999 in southwestern Germany. Can. J. For. Res. 40, 1636-1652. https://doi.org/10.1139/X10-099 bark beetle disturbances in forest landscapes. Landsc. Ecol. 32, 1485-1498. https://doi.org/10.1007/s10980-016-0396-4

Seidl, R., Schelhaas, M.-J., Lexer, M.J., 2011. Unraveling the drivers of intensifying forest disturbance regimes in Europe. Glob. Change Biol. 17, 2842-2852. 
https://doi.org/10.1111/j.1365-2486.2011.02452.x

872 Seidl, R., Schelhaas, M.-J., Rammer, W., Verkerk, P.J., 2014. Increasing forest disturbances in Europe and their impact on carbon storage. Nat. Clim. Change 4, 806-810.

874 https://doi.org/10.1038/nclimate2318

875

Seidl, R., Thom, D., Kautz, M., Martin-Benito, D., Peltoniemi, M., Vacchiano, G., Wild, J.,

876 Ascoli, D., Petr, M., Honkaniemi, J., Lexer, M.J., Trotsiuk, V., Mairota, P., Svoboda, M., Fabrika, M., Nagel, T.A., Reyer, C.P.O., 2017. Forest disturbances under climate change. Nat. Clim. Change 7, 395-402. https://doi.org/10.1038/nclimate3303

Suvanto, S., Henttonen, H.M., Nöjd, P., Mäkinen, H., 2018. High-resolution topographical 880 information improves tree-level storm damage models. Can. J. For. Res. 48, 721728. https://doi.org/10.1139/cjfr-2017-0315

Suvanto, S., Henttonen, H.M., Nöjd, P., Mäkinen, H., 2016. Forest susceptibility to storm damage is affected by similar factors regardless of storm type: Comparison of thunder storms and autumn extra-tropical cyclones in Finland. For. Ecol. Manag. 381, 17-28. https://doi.org/10.1016/j.foreco.2016.09.005

Tomppo, E., Haakana, M., Katila, M., Peräsaari, J., 2008. Multi-Source National Forest Inventory: Methods and Applications, Managing Forest Ecosystems. Springer Netherlands.

Tomppo, E., Heikkinen, J., Henttonen, H.M., Ihalainen, A., Katila, M., Mäkelä, H., Tuomainen, T., Vainikainen, N., 2011. Designing and Conducting a Forest Inventory -

Valinger, E., Fridman, J., 2011. Factors affecting the probability of windthrow at stand level as a result of Gudrun winter storm in southern Sweden. For. Ecol. Manag. 262, 398403. https://doi.org/10.1016/j.foreco.2011.04.004

Valinger, E., Fridman, J., 1997. Modelling probability of snow and wind damage in Scots pine stands using tree characteristics. For. Ecol. Manag. 97, 215-222. 
899 Valinger, E., Kempe, G., Fridman, J., 2014. Forest management and forest state in southern Sweden before and after the impact of storm Gudrun in the winter of 2005. Scand. J. For. Res. 29, 466-472. https://doi.org/10.1080/02827581.2014.927528

Venäläinen, A., Laapas, M., Pirinen, P., Horttanainen, M., Hyvönen, R., Lehtonen, I., Junila,

903 P., Hou, M., Peltola, H.M., 2017. Estimation of the high-spatial-resolution variability in extreme wind speeds for forestry applications. Earth Syst. Dyn. 8, 529-545.

905 https://doi.org/10.5194/esd-8-529-2017

Wallentin, C., Nilsson, U., 2014. Storm and snow damage in a Norway spruce thinning experiment in southern Sweden. For. Int. J. For. Res. 87, 229-238.

908 https://doi.org/10.1093/forestry/cpt046

Wand, M., 2015. KernSmooth: Functions for Kernel Smoothing Supporting Wand \& Jones (1995), R package version 2.23-15. https://CRAN.Rproject.org/package=KernSmooth.

Wood, S., 2017. Generalized Additive Models: An Introduction with R, Second Edition, 2nd edition. ed.

914 Wood, S.N., 2011. Fast stable restricted maximum likelihood and marginal likelihood

915 estimation of semiparametric generalized linear models. J. R. Stat. Soc. Ser. B Stat. $916 \quad$ Methodol. 73, 3-36.

917 Wood, S.N., Scheipl, F., 2017. gamm4: Generalized Additive Mixed Models using "mgcv" 918 and "Ime4". R package version 0.2-5. https://CRAN.R-project.org/package=gamm4. 


\section{Supplementary materials}

921 S1. The damage density ratio variable

922 S2. GAM model results

923 S3. BRT parameter tuning

924 S4. GLM variance-covariance matrix 